\title{
Meningkatkan Eksistensi Agroindustri Temerodok melalui Pengembangan Varian Sebagai Wujud Ekonomi Kreatif di Desa Sakra
}

\author{
Roy Setiadi ${ }^{1}$, Aminah ${ }^{1}$, Baiq Sari Supriantini ${ }^{1}$, Lalu Randa Hazri Ramdani ${ }^{1}$, Siti Soleha ${ }^{1}$, Hamidsyukrie \\ 1,Syahrial Ayub ${ }^{1}$, Muhammad Taufik ${ }^{1}$, Syafruddin ${ }^{1}$, Saprizal Hadisaputra ${ }^{{ }^{*}}$
}

${ }^{1}$ Fakultas Keguruan dan Ilmu Pendidikan, Universitas Mataram, Indonesia

DOI: https:// doi.org/10.29303/ujcs.v2i1.9

Article Info

Received: December 25 ${ }^{\text {th }}, 2020$

Revised: February 25th 2021

Accepted: March $4^{\text {th }}, 2021$

\begin{abstract}
Pengabdian kepada masyarakat ini bertujuan untuk meningkatkan eksistensi Agroindustri Temerodok melalui pengembangan varian rasa yang baru sebagai wujud ekonomi kreatif di Desa Sakra, Kabupaten Lombok Timur. Kegiatan pengabdian masyarakat ini dilaksanakan selama 45 hari.Dilakukan pelatihan dan produksi produk Temerodok dilakukan dua kali dalam seminggu. Adapun Cara pembuatan Temerodok masih teknik sederhana dengan tetak mempertahankan kearifan lokal. Produk Temerodok ini setelah meningkatkan eksistensi dan mengembangkan varian sudah dikenal oleh masyarakat luas dan bukan hanya masyarakat di Desa Sakra. Varian yang dikembangkan juga sangat banyak diminati oleh masyarakat luas khususnya semua kalangan. Dalam hal pengemasan menggunakan paper bag supaya ramah lingkungan dan agar terlihal menarik serta dapat menjadi salah satu oleh oleh khas daerah. Pendirian usaha ini merupakan wujud dari sebagian proses pengembangan untuk meningkatkan eksistensi agroindustri temerodok.

Kata Kunci: Temerodok; Agroindustri; Eksistensi; Kreatif
\end{abstract}

Abstract: This community service aims to improve the existence of the Temerodok Agroindustry through the development of new flavors as a form of creative economy in Sakra Village, East Lombok Regency. This community service is carried out for 45 days and is trained and produced twice a week. The method of making Temerodok is still a simple technique by not preserving the local wisdom. This Temerodok product, having expanded its existence and developed variants, is recognized by the wider community and not just the people of Sakra Village. The developed variant is also very popular with the wider community, especially in all circles. In terms of packaging, use a paper bag so that it is environmentally friendly and looks attractive and can be one of the local specialties. The establishment of this company is part of the development process to improve the existence of Temerodok's agro industry

Keywords: Temerodok; Agroindustry; Existence; Creative

Sitasi : Setiadi, R., Aminah, A., Supriantini, B., Ramdani, L., Soleha, S., Hamidsyukrie, H., Ayub, S., Taufik, M., Syafruddin, S., \& Hadisaputra, S. (2021). Meningkatkan Eksistensi Agroindustri Temerodok melalui Pengembangan Varian Sebagai Wujud Ekonomi Kreatif di Desa Sakra. Unram Journal of Community Service, 2(1). doi:https://doi.org/10.29303/ujcs.v2i1.9

\section{Pendahuluan}

Pulau Lombok merupakan salah satu wilayah di Provinsi Nusa Tenggara Barat (NTB) yang memiliki kekayaan alam contohnya di bidang pertanian, yang dimana masyarakat masih memanfaatkannya. Agroindustri adalah kegiatan pengolahan hasil-hasil pertanian untuk menghasilkan barang jadi atau bahan baku bagi industri lainny (Suparmin, 2018). Agroindustri di Pulau Lombok sangat banyak misalnya gula aren (Suparmin, 2018), pisang Nadya (Tanaya, 2020), bantal gapuk (Aini \&Anwar, 2020), tempe (Hidayat, 2020) dan minyak kelapa VCO (Tajidan, 2019) dan temerodok. Agroindustri industri gula aren merupakan salah satu industri kecil pertanian yang telah lama ada di Indonesia dan pengolahannya masih sederhana. Agroindustri pisang Nadya merupakan produsen produk olahan pisang seperti pisang sale dan kripik pisang. Usaha jajanan bantal merupakan salah satu sektor usaha rumahan

\footnotetext{
*Email: rizal@unram.ac.id
} 
yang sifatnya dikerjakan secara turun temenurun. Jajanan tradisional yang berasal dari Lombok memiliki cita rasa yang khas dan bentuk yang unik sehingga menarik minat konsumen. Salah satu jajanan lombok yaitu temerodok. Temerodok berawal dari usaha keluarga turun-temurun dan pada akhirnya meluas sehingga menjadi mata pencaharian penduduk kampung.

Temerodok merupakan jajanan tradisional yang terbuat dari campuran bahan sederhana seperti tepung ketan, telur, gula dan garam yang berbentuk unik menyerupai keong. Temerodok sendiri berasal dari daerah Sakra bagian timur pulau Lombok. Jajanan temerodok umumnya memiliki cita rasa manis dan tekstur yang lunak sehingga banyak digemari oleh masyarakat Lombok, akan tetapi tidak sedikit masyarakan yang mulai melupakan jajanan tradisional karena dianggap memiliki nilai gizi yang kurang sehingga beralih pada makanan modern yang biasanya memiliki nilai gizi yang lebih banyak (Yusa, 2020; Zainuri, 2016).

Cara pembuatan Temerodok masih sangat sederhana yaitu dengan menggunakan kedua tangan sehingga butuh kesabaran dan ketelatenan. Keberadaan Agroindustri kecil dan industri rumah tangga di Kecamatan Sakra diharapkan dapat menjadi penggerak pertumbuhan ekonomi lokal di wilayah tersebut. Selain sektor pertanian terutama dalam rangka peningkatan kemampuan ekonomi masyarakat pedesaan. Agroindustri Temerodok masih dihadapkan pada berbagai masalah sehingga menyebabkan layak atau tidaknya diusahakan. Pada umumnya kendala yang sering dihadapi oleh usaha kecil adalah modal sehingga tidak pernah melakukan inovasi yang baru untuk bersaing dengan produk yang saat ini sudah banyak berkembang, pengetahuan teknologi yang masih kurang dan kreatifitas masyarakat yang kurang sehingga dapat mempengaruhi kontinuitas, eksistensi dan kualitas.

Berdasarkan uraian diatas maka penulis mencoba mengarahkan pengabdian masyarakat pada menghadirkan suatu alternatif lain yaitu dengan mengolah jajanan tersebut menjadi berbagai varian rasa yang lebih diminati oleh masyarakat milenial. Kemudian akan dilakukan pembaharuan dalam hal kemasan supaya lebih menarik, modern dan ramah lingkungan.

\section{Metode Pelaksanaan}

Pelaksanaan KKN New Normal dilaksanakan dengan memperhatikan protokol kesehatan untuk mengurangi penyebaran Covid-19. Waktu pelaksanaannya dimulai dari tanggal 23 November 2020 - 7 Januari 2021. Tempat pelaksanaannya di Desa
Sakra, Kecamatan Sakra, Kabupaten Lombok Timur. Tahapan pelaksanaan antara lain tahap persiapan, tahap produksi, tahap promosi, tahap pemasaran, tahap evaluasi dan tahap pembuatan video dan leaflet.

1. Tahap Persiapan

Pada tahap persiapan ini dilakukan selama empat hari yaitu pada hari Rabu- Senin tanggal 2530 November 2020. Tahap persiapan terdiri dari diskusi program $\mathrm{KKN}$, mengerjakan proposal $\mathrm{KKN}$, observasi kegiatan pembuatan temerodok di Desa Sakra,

2. Tahap Produksi

Produksi dilakukan selama 9 kali selama kegiatan KKN berlangsung. Produksi dilakukan sekali dalam seminggu. Dalam produksi Temerodok ini, kemasan dibuat dengan menggunakan bungkus nasi. Alat produksi adalah wajan, sutil, gas, nampan, saringan, steples, bungkus nasi, dan gunting. Bahan produksi seperti paper bag, tepung ketan, telur, perisa jagung bakar, perisa barbeque, perisa balado, perisa coklat, perisa jagung manis, stiker, isi steples, dan minyak goreng.

Langkah-langkah produksi adalah beras ketan direndam selama kurang lebih 30 menit. Beras ketan yang telah direndam kemudian ditiris dan digiling lalu dimasukkan beras ketan yang sudah halus dengan berat 1 (satu) $\mathrm{Kg}$ ke nampan. Setelah itu, masukkan 9 (sembilan) butir telur dan aduk hingga kalis menjadi adonan. Adonan yang sudah kalis kemuadian didiamkan sekitar 5 (lima) menit kemudian bentuk adonan menjadi Temerodok. Adonan yang sudah dibentuk kemudian digoreng dengan api sedang hingga kecokelatan lalu angkat kemudian tiriskan minyak. Diamkan Temerodok yang sudah diangkat beberapa saat, lanjutkan dengan mencampurkan Temerodok dengan varian rasa. Terakhir masukkan Temerodok kedalam kemasan.

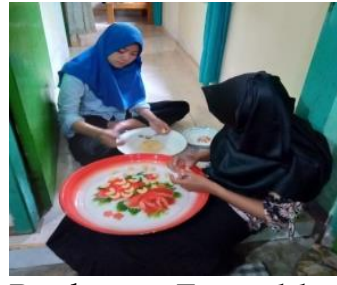

Pembuatan Temerodok

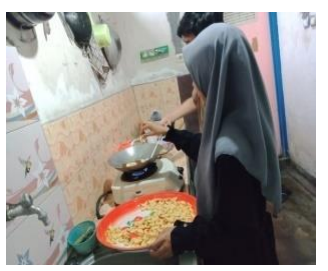

Tahap penggorengan Temerodok

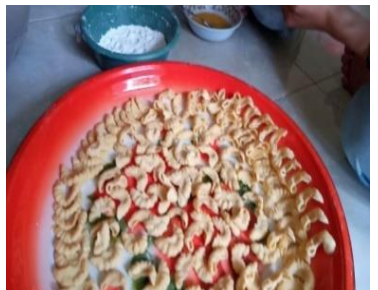

Temerodok yang sudah jadi

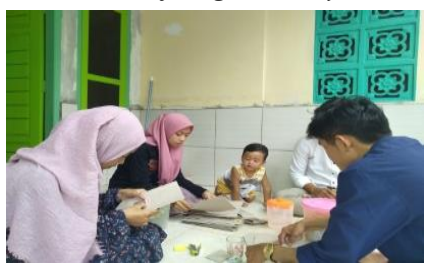

Tahap pengemasan Temerodok 


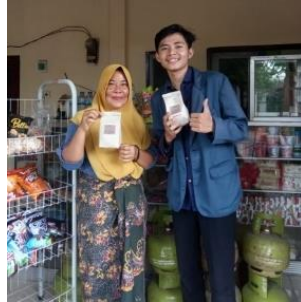

Tahap pemasaran Temerodok Tiyang

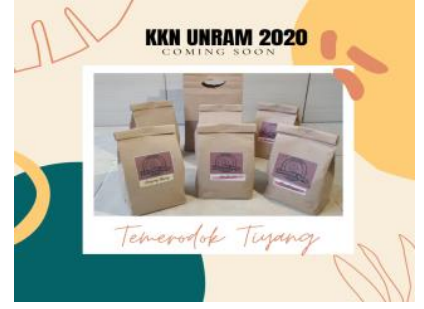

Kemasan Temerodok Tiyang
3. Tahap Promosi

Tahap promosi dilakukan dengan memanfaatkan media sosial seperti facebook, WA dan berjualan langsung di sekitaran Desa Sakra. Dalam tahap promosi ini, kami menggunakan video dan gambar leaflet untuk mempromosikan produk kami. Penjualan produk ini, bebas ongkir untuk sekitaran Desa Sakra, sedangkan untuk luar Desa Sakra terdapat ongkir yang disesuaikan dengan jarak yang ditempuh.

4. Tahap Evaluasi

Tahap evaluasi dilakukan selama tujuh hari dengan memperbanyak promosi produk Temerodok ke gedai-gedai yang ada disekitaran Desa Sakra.
5. Tahap Pembuatan Video dan Leaflet

Pembuatan leaflet dilakukan pada hari Rabu 2 Desember 2020, selain sebagai luaran KKN leaflet juga kami gunakan untuk mempromosikan Produk Temerodok. Sedangkan pengambilan video dilakukkan pada hari Sabtu, 2 Januari 2021. Video berisi tentang berbagai program yang telah dilakukan selama KKN berlangsung dan yang paling utama yaitu produksi Temerodok.

\section{Hasil dan Pembahasan}

\section{Biaya Produksi dan Pendapatan Agroindustri Temerodok}

Dalam penelitian ini analisis biaya dan pendapatan difokuskan pada analisis biaya tetap (fixed cost), biaya variabel (variabel cost), produksi dan nilai produksi pada agroindustri temerodok di Desa Sakra Kecamatan Sakra Kabupaten Lombok Timur Tahun 2020.

Adapun rincian biaya produksi yang dikeluarkan pada agroindustri temerodok dapat dilihat pada Tabel 1.

Tabel 1. Rincian biaya produksi yang dikeluarkan pada agroindustri Temerodok (BahanHabisPakai)

\begin{tabular}{|c|c|c|c|c|}
\hline No. & Nama Bahan & Jumlah & Harga Satuan & Total harga \\
\hline 1. & Paper bag & 4 pack & Rp. $14.000,00$ & Rp. 56.000,00 \\
\hline 2. & Tepung ketan & $20 \mathrm{~kg}$ & Rp. $25.000,00$ & Rp. $500.000,00$ \\
\hline 3. & Telur & 450 butir & Rp. $45.000,00$ & Rp. $675.000,00$ \\
\hline 4. & Perisa jagung bakar & $1 \mathrm{~kg}$ & Rp. $50.000,00$ & Rp. $50.000,00$ \\
\hline 5. & Perisa barbeque & $1 \mathrm{~kg}$ & Rp. $50.000,00$ & Rp. $50.000,00$ \\
\hline 6. & Perisa balado & $1 \mathrm{~kg}$ & Rp. $48.000,00$ & Rp. $48.000,00$ \\
\hline 7. & Perisa coklat & $1 \mathrm{~kg}$ & Rp. $58.000,00$ & Rp. $58.000,00$ \\
\hline 8. & Perisa jagung manis & $1 \mathrm{~kg}$ & Rp. $50.000,00$ & Rp. $50.000,00$ \\
\hline 9. & Stiker & 200 biji & Rp. $1.000,00$ & Rp. $200.000,00$ \\
\hline 10. & Isi steples & 3 pack & Rp. $2.000,00$ & Rp. $6.000,00$ \\
\hline 11. & Minyak goreng & $20 \mathrm{~kg}$ & Rp. $14.000,00$ & Rp. $280.000,00$ \\
\hline 12. & Steples & 1 & Rp. $10.000,00$ & Rp. $10.000,00$ \\
\hline 13. & Gas & 1 & Rp. $20.000,00$ & Rp. $20.000,00$ \\
\hline 14. & Bensin & 12 liter & Rp. 8.000,00 & Rp. $96.000,00$ \\
\hline 15. & Administrasi & & & Rp. $100.000,00$ \\
\hline 16. & Publikasi & & & Rp. $160.000,00$ \\
\hline 17. & Print Proposal & & & Rp. $30.000,00$ \\
\hline Jumlah & & & & Rp. $2.839 .000,00$ \\
\hline
\end{tabular}

\section{Analisis Pendapatan Usaha Agroindustri Temerodok}

Pendapatan adalah selisih antara nilai produksi dikurangi dengan biaya produksi pada agroindustri temerodok yang dinyatakan dalam satuan rupiah. Hasil penilitian terhadap jumlah produksi, nilai produksi, keuntungan pada agroindustri jajan temerodok di Desa Sakra Kecamatan Sakra Kabupaten Lombok Timur adapun analisisnya sebagai berikut :Modal awal pembuatan temerodok dalam 5 minggu atau dalam 10 kali produksi yakni sebesar Rp 2.389.000 menghasilkan 500 kemasan. Total biaya bahan = biaya baku + biaya perlengkapan + biaya lainnya $=R p$ 2.389.000. Penentuan harga jual temerodok. Harga pokok produksi $=$ total biaya $/$ hasil produksi selama 5 minggu $=R p 2 \cdot 389.000 / 500=\operatorname{Rp} 5,000$. Jadi, harga pokok 1 kemasan temerodok yakni Rp 5,000. Harga jual temerodok $=$ harga pokok + laba yang diinginkan $=\mathrm{Rp}$ $5,000+\operatorname{Rp} 3,000=\operatorname{Rp~8,000/pack~}$ 


\section{Perhitungan laba atau rugi}

Dalam 5 minggu akan memproduksi temerodok sebanyak 10 kali yaitu pada hari senin dan kamis, dalam satu minggu kami memproduksi 50 pack temerodok dan memasarkan produk temerodok sebanyak 2 kali seminggu, sehingga dalam 5 minggu kami memasarkan temerodok sebanyak 10 kali.Perhitungan laba/rugi $=$ (hasil produksi $\times$ harga jual $)-$ modal total $=(500 \times \operatorname{Rp} 8.000)-\operatorname{Rp} 2.389 .000=$ $\operatorname{Rp} 4.000 .000-\operatorname{Rp} 2.389 .000=\operatorname{Rp} 1.611 .000$. Keuntungan yang kami dapatkan selama 5 minggu yakni Rp 1.611 .000

\section{Analisis BreakEvent Point}

Tabel 2. Analisis BreakEvent PointBEP

\begin{tabular}{llll}
\hline $\begin{array}{l}\text { Total } \\
\text { Pack }\end{array}$ & $\begin{array}{l}\text { Harga jual/ } \\
\text { pack }\end{array}$ & $\begin{array}{l}\text { Biaya variabel/ } \\
\text { pack }\end{array}$ & $\begin{array}{l}\text { Biayaadministrasi } \\
\text { dan pemasaran }\end{array}$ \\
\hline 500 & Rp5,000 & Rp3,000 & Rp 1000 \\
Biaya & Rp2.389.000 & & Rp3.000.000 \\
\hline
\end{tabular}

\section{FaktorLingkunganEksternal}

Faktor lingkungan eksternal adalah faktor yang berada diluar agroindustri temerodok yang dapat mempengaruhi usaha tersebut. Adapun unsurunsurnya dapat diuraikan sebagai berikut: 1) Faktor Eksternal Peluang yaitu: (a) inovasi produk, (b) adanya perhatian pemerintah, (c) merupakan komoditi khas sakra, (d) sebagai produk cemilan dan oleh-oleh, dan (e) pangsa pasar masih luas. 2) Faktor Eksternal Ancaman yaitu: (a) fluktuasi harga bahan baku, (b) jumlah konsumen akhir yang berfluktuasi, dan (c) adanya pesaing antar sesama pengusaha temerodok.
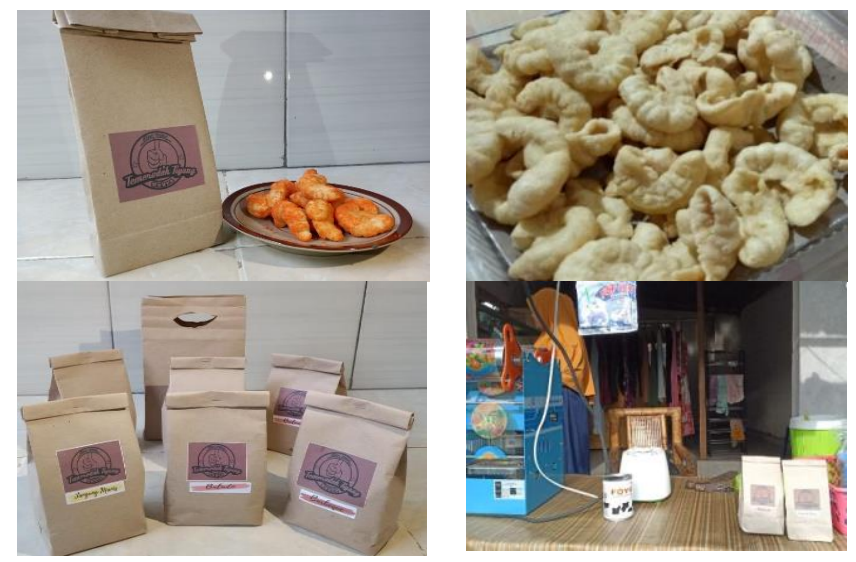

Gambar 1. InovasijajananTremodok yang dihasilkan

\section{Faktor Lingkungan Internal}

Faktor lingkungan internal adalah faktor yang berada di dalam usaha agroindustri temerodok itu sendiri. Adapun faktor internal pada agroindustri temerodok adalah sebagai berikut: 1) Faktor Internal Kekuatan yaitu: (a) lokasi usaha yang strategis, (b) harga produk terjangkau, (c) ketersediaan bahan baku, (d), memiliki tenaga kerja yang terampil dan berpengalaman, dan (e) merupakan sentra industri temerodok.
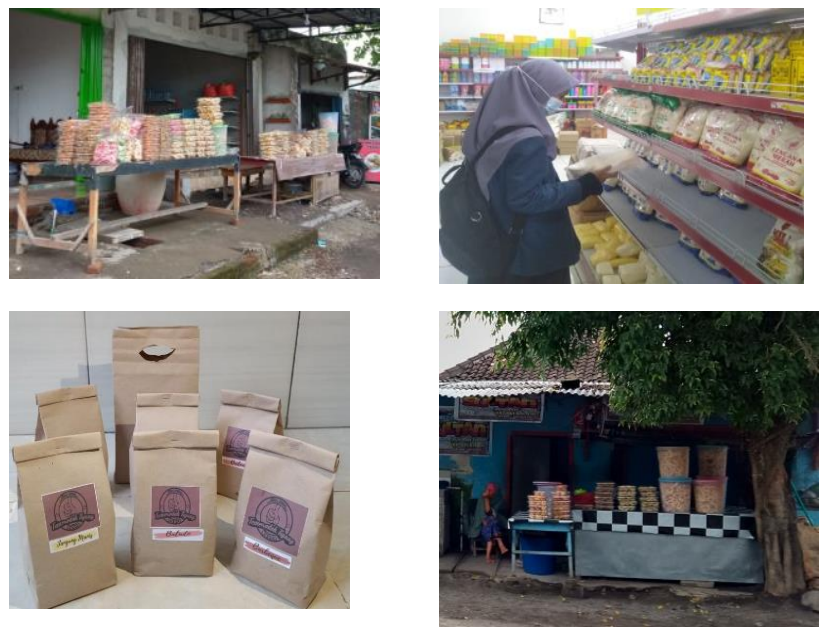

Gambar 2. Kegiatan usaha Tremedok

\section{Keberlanjutan Usaha}

Produk Temerodok adalah jajanan khas sakra yang memiliki provit menjanjikan dengan ketersediaan ketan sebagai bahan dasar yang dicampur dengan telur. Selain itu Temerodok mempunyai keunggulan dari sisi pengemasan yang inovatif dan kreatif dengan memberikan ulasan singkat mengenai temorodok. Produk Temerodok juga memiliki daya tarik tersendiri karena memiliki varian rasa yang kekinian dan pengemasan produk yang futuristik yang mampu menarik minat konsumen. Beberapa keunggulan produk diatas merupakan aspek-aspek yang menjamin keberlanjutan usaha produk Temerodok. Bantuan pemerintah juga diharapkan dalam proses pengembangan usaha produk Temerodok agar dapat melebarkan sayap serta dapat bersaing pada level pasar yang lebih besar lagi. Hal ini karena produk Temerodok tidak hanya diproduksi dan dipasarkan untuk mendapatkan keuntungan ekonomi semata tetapi Temerodok juga memberikan nilai inoatif tinggi kepada masyarakat.

\section{Kesimpulan}

Berdasarkan hasil dan pembahasan yang sudah tertera diatas dapat disimpulkan bahwa Desa Sakra merupakan desa yang banyak memiliki potensi salah satunya di bidang Perdagangan. Dengan demikian potensi tersebut harus dikembangkan agar dapat memberikan manfaat bagi masyarakat desa Sakra. Salah satunya dengan diadakannya pembuatan produk temerodok, dimana program tersebut dengan memanfaatkan agroindustri yang ada di desa sakra 
sehingga potensi dengan mengembangkan temerodok di desa Sakra menghasilkan manfaat serta keuntungan bagi masyarakat. Namun temerodok yang ada di desa Sakra belum terlalu dikenal oleh masyarakat luas. Para pembuat temerodok ini masih menjual dagangannyadi kios kecil dan pasar tradisional, sehingga keuntungan yang diperoleh bisa dikatakan sedikit. Kemudian dengan memanfaatkan teknologi yang ada perlu pemasaran yang lebih praktis seperti, memanfaatkan teknologi yang ada melalui media social. Untuk memasarkan produk tersebut maka diadakannya sosialisasi strategi pemasaran temerodok, dimana saat sosialisai ini dibuatkan akun social media yaitu facebook dan instagram yang akan disebarkan di wilayah luar desa sakra Pembuat temerodok juga diberi pengarahan bagaimana cara menggunakan social media yang akan digunakan untuk memasarkan produk tersebut. Semua yang terlaksana selama kehadiran mahasiswa KKN Universitas Mataram di Desa Sakra diharapkan mampu membantu masyarakat maupun pihak kantor desa dalam upaya pemecahan masalah masyarakat dan setidaknya akan membawaperubahan untuk membangun masyarakat yang madani.

\section{Saran}

Berdasarkan hasil penelitian dan kesimpulan yang telah diuraikan maka disarankan:

Bagi pengusaha agroindustri temerodok supaya memperbaiki kelemahan kelemahan yang ada pada usaha tersebut agar dapat berkembang lebih baik lagi salah satunya dengan cara meningkatkan kualitas produk dan menjalin kerjasama dengan distributor baik didalam maupun diluar daerah.

Bagi pemerintah diharapkan terus mendukung usaha agroindustri temerodok dengan menyediakan akses permodalan guna pengembangan agroindustri temerodok kedepannya.

Bagi peniiti diharapkan di masa yang akan datang dapat digunakan sebagai salah satu sumber data untuk penelitian selanjutnya dan dilakukan penelitian lebih lanjut berdasarkan faktor lainnya yang berhubungan dengan penelitian sejenis

\section{Daftar Pustaka}

Aini, R., \& Anwar, M. (2020). Prospek dan Strategi Pemasaran Agroindustri Jajanan Bantal Gapuk Kabupaten Lombok Timur. Jurnal Ilmiah Rinjani: Media Informasi Ilmiah Universitas Gunung Rinjani. 8 (2). 92-103.

Hs, I.A., Yusa, N.M., \& Wiadnyant, A.I.S. (2020) Pengaruh Perbandingan Tepung Ketan Putih Dengan Tepung Kacang Merah (Phaseolus
Vulgaris L.) Terhadap Karakteristik Temerodok. Jurnal Ilmu Dan Teknologi Pangan (ITEPA). 9(1). 30-37.

Pasaribu, A.M. (2012). Perencanaan dan Evaluasi Proyek Agribisnis Konsep dan Aplikasinya. Lily Publisher: Yogyakarta.

Santi, R. D. Bq. (2018). Analisis Kelayakan Usaha Dan Strategi Pengembangan Agroindustri Temerodok Di Kecamatan Sakra Kabupaten Lombok Timur. Jurnal Ilmiah Rekayasa Pertanian Dan Biosistem. 8(2). 230-235.

Soekartawi. (2006). Analisis Usaha tani. PT. Raja Grafindo Persada: Jakarta.

Suparmin, I. (2018). “EfisiensiAlokatif Agroindustri GulaArenDi Kabupaten Lombok Barat. AGROTEKSOS: Agronomi Teknologi Dan Sosial Ekonomi Pertanian. 7(3). 69-80.

Tajidan, T., Efendy, E., Halil, H., \& Fernandez, F. E. (2019). Pendampingan Pembiayaan Pada Unit Bisnis Agroindustri Minyak Kelapa Dara Di Kabupaten Lombok Utara. Jurnal Ilmiah Abdi Mas TPB Unram. 1 (2).

Tajidan, T., Halil, H., Efendy, E., \& Fernandez, F. E. (2019).NilaiTambah VCO Pada Unit Bisnis Agroindustri Andana Di Kabupaten Lombok Utara. Jurnal Gema Ngabdi. 1 (3). 92-102.

Tanaya, I. G. L. P., Yasa, I. W. S., \& Sukmawati, S. (2020). Model Pengembangan Agroindustri Berbasis Pisang Di Desa Gondang Kabupaten Lombok Utara. Jurnal PEPADU. 1(3). 415-422.

Zainuri, Z., Zaini, A., Werdiningsih, W., \&Sjah, T. (2016). Keragaman Pangan Lokal Di Pulau Lombok Untuk Menunjang Pengembangan Pariwisata. Agritech, 36(2), 206-218. 